DOI: 10.12737/article_5c92016e1314b2.49705560

УДК 614.842

\author{
ТУШЕНИЕ ЛЕСНЫХ ГОРЮЧИХ МАТЕРИАЛОВ ГИДРОГЕЛЯМИ \\ НА ОСНОВЕ ГИДРОКСИДА АЛЮМИНИЯ \\ аспирант О.А. Ивченко ${ }^{1}$ \\ кандидат химических наук, доцент Панкин К.Е. ${ }^{1}$ \\ 1 - ФГБОУ ВО «Саратовский государственный аграрный университет \\ имени Н.И. Вавилова», г. Саратов, Российская Федерация
}

Тушение лесных пожаров имеет ряд особенностей перед тушением пожаров в промышленных и жилых зданиях. Они заключаются в составе и строении лесных горючих материалов, способствующих образованию многочисленных очагов тления, и более низком значении пожарной нагрузки (3-5 раз) для лесных пожаров по сравнению с техногенными. Это накладывает ограничения как на технологию тушения пожара, так и на оборудование, используемое при тушении, и приводит к неоправданно высокому расходу воды на тушение, а также необходимости введения дополнительных операций окарауливания и дотушивания, что отвлекает силы и средства тушения пожаров от своей главной задачи. В данной работе рассмотрен вопрос повышения эффективности тушения лесных горючих материалов с использованием в качестве огнетушащего вещества гидрогеля, полученного на основе гидроксида алюминия. Исследования огнетушащей способности выбранных огнетушащих составов проводили по специальной методике, имитирующей горение лесных горючих материалов. Регистрация эффективности огнетушения осуществлялась наблюдением четырех параметров: общего массового расхода огнетушащего состава на тушение, времени прекращения пламенного горения при тушении, количества операций тушения, общего времени тушения пожара. Исследована огнетушащая способность растворов с различной концентрацией гидрогеля на основе гидроксида алюминия в сравнении с огнетушащей способностью воды. Показано, что наилучшей огнетушащей способностью обладает гидрогель с концентрацией 52-126 г /15 кг воды. Кроме этого, для сравнения огнетушащей способности гидрогеля применяли растворы кальцинированной соды и сульфата натрия в воде как компонентов огнетушащего состава. Серьезного вклада в огнетушение эти компоненты не вносят, поэтому огнетушащий эффект полностью обусловлен гидрогелем на основе гидроксида алюминия. На основании полученных данных определен расход раствора гидрогеля на основе гидроксида алюминия в сравнении с водой и наименьшая его концентрация, сохраняющая огнетушащий эффект, предложен вероятный механизм огнетушащего действия гидрогеля.

Ключевые слова: лесные пожары, степные пожары, низовые пожары, тушение пожаров, гидрогель

\title{
EXTINGUISHING FOREST FLAMMABLE MATERIALS WITH HYDROGELS BASED ON ALUMINUM HYDROXIDE
}

Post-graduate student O.A. Ivchenko ${ }^{1}$

$\mathrm{PhD}$ (Chemistry), Associate Professor K.E. Pankin ${ }^{1}$

1- FSBEI HE «Saratov State Vavilov Agrarian University», Saratov, Russian Federation

\begin{abstract}
Forest fires extinguishment has a number of features in comparison with extinguishing fires in industrial and residential buildings. These are composition and structure of forest flammable materials, contributing to the formation of numerous glow nests and lower value of the fire load (3-5 times) for forest fires in comparison with man-made fires. This imposes restrictions both on the fire extinguishing technology and on the equipment used for extinguishing and leads to unreasonably high water consumption for extinguishing, as well as the need to introduce additional operations of collecting and extinguishing, which distracts the forces and means of extinguishing fires from its main task. In this paper, the issue of increasing the efficiency of extinguishing forest flammable materials using a hydrogel based on alu-
\end{abstract}




\section{Природопользование}

minum hydroxide as an extinguishing agent is considered. Investigations of the fire extinguishing ability of selected fire extinguishing compositions were carried out according to a special technique that simulates burning of forest combustible materials. The registration of the effectiveness of fire extinguishing was carried out by observing four parameters: the total mass flow rate of the extinguishing agent for extinguishing, the time for stopping fiery burning during extinguishing, the number of extinguishing operations, and the total time for extinguishing the fire. The fire extinguishing ability of solutions with different concentrations of hydrogel based on aluminum hydroxide was investigated in comparison with the fire extinguishing ability of water. It is shown that the best fire extinguishing ability has hydrogel with a concentration of 52-126 g /15 kg of water. In addition, anhydrous sodium carbonate and sodium sulphate water solutions as components of the fire extinguishing composition were used to compare the extinguishing ability of the hydrogel. These components do not make a serious contribution to fire extinguishing; therefore the fire extinguishing effect is completely due to the hydrogel based on aluminum hydroxide. Based on the obtained data, the flow rate of the hydrogel solution based on aluminum hydroxide in comparison with water and its lowest concentration was determined, which preserves the extinguishing effect. A probable mechanism of the extinguishing action of the hydrogel is proposed.

Keywords: forest fires, steppe fires, ground fires, fire extinguishing, hydrogel

Лесные и степные пожары являются естественными процессами, происходящими в природе вне зависимости от присутствия или отсутствия человека или его деятельности. В связи с масштабным преобразованием природы, которое человек осуществляет на всем земном шаре, природные пожары были поставлены человеком «вне закона», т. к. пожары наносят ущерб материальным ценностям и ведению хозяйственной деятельности. Для борьбы с природными пожарами стали применяться мероприятия по профилактике и тушению лесных и степных пожаров. Лесные пожары происходят в теплое время года, которое длится в Российской Федерации (в зависимости от региона) 4-9 месяцев, в течение которых нередко формируются засушливые периоды, характеризующиеся низким уровнем или вовсе отсутствием выпадения атмосферных осадков. Лесная и степная местности постепенно высыхают, и появляется благодатная «почва» для возникновения и развития природных пожаров.

Лесной пожар необходимо тушить - для этого применяются огнетушащие средства, которые прекращают взаимодействие лесных горючих материалов (ЛГМ) с воздухом. Чаще всего таким огнетушащим средством является вода, обладающая необходимым набором физико-химических свойств, делающих ее пригодной в качестве огнетушащего вещества. Вода применяется для тушения лесных и степных пожаров как при тушении наземными, так и авиационными средствами. Тем не менее, вода обладает целым рядом недостатков, осложняющих процесс тушения пожаров: высокое поверхностное натяжение воды и ее растворов, а в связи с этим низкая эффективность смачивания различных поверхностей, довольно низкая температура кипения $\left(100{ }^{\circ} \mathrm{C}\right)$ и т. п.

Несмотря на то, что Российская Федерация не относится к засушливым регионам планеты, в теплое время года может наблюдаться значительный недостаток воды, пригодной для применения в ходе тушения лесных пожаров. В засушливое время вода становится ценным ресурсом, т. к. взять ее в лесной или степной местности просто неоткуда изза пересыхания небольших рек и ручьев, понижения уровня воды в водохранилищах (небольших озерах, прудах, заводях и т. п.) и др. Поэтому на передний план выдвигаются задачи поиска и доставки воды к месту тушения, пожара, а также задача сокращения расхода воды при тушении природного пожара, как следует понимать, обе эти задачи взаимосвязаны между собой. Первая задача решается чисто технически и находится в ведении органов местного самоуправления, хотя на практике это приводит к отвлечению части сил и средств тушения пожара на доставку воды к месту тушения, что приводит к растягиванию по времени проводимых операций, снижает эффективность тушения пожаров и ведет к возникновению значительного материального и финансового ущерба лесному и сельскому хозяйству. А вот вторая задача носит научнотехнический характер, а поиск способов и приемов 


\section{Природопользование}

снижения расхода огнетушащего средства при тушении лесного пожара является целью данной работы.

Расход воды для тушения природного пожара никаким образом не регламентируется. Да это и невозможно, т. к. контроль ликвидации пожара осуществляется оператором визуально (по наличию признаков пламенного горения и интенсивности выделения дыма при беспламенном режиме горения), а сложный характер строения ЛГМ (при низовых лесных пожарах - лесного опада) обуславливает многократный переход пламенного горения в беспламенное и обратно с образованием очагов тления, в том числе и скрытых, являющихся источниками повторного возгорания. Кроме этого, разогретые зоны могут сохраняться в трещинах стволов деревьев, образующихся в результате термического воздействия, выгорания древесины, сушки и уменьшения ее объема. Такое положение дел вынуждает пожарных осуществлять операции дотушивания и проливки кромки пожара и участков горельников, что значительно увеличивает расход воды, отвлекает часть сил и средств от реализации действий по решающему направлению. Ориентировочные значения расхода воды при тушении лесных пожаров представлены в работах $[1,2]$, возможно, эти значения несколько занижены.

Для снижения расхода воды при тушении лесного пожара необходимо каким-либо образом улучшить те свойства воды, которые относятся к ее недостаткам, а возможно, и расширить возможности ее огнетушащего действия путем реализации других принципов пожаротушения. Вода относится к типичным огнетушащим веществам охлаждающего действия [3], для которой реализация других принципов, таких как изоляция, разбавление и ингибирование при тушении лесных пожаров невозможна. Для расширения возможностей воды применяют различного рода органические и неорганические добавки, модифицирующие ее свойства, к примеру, смачиватели - поверхностно-активные вещества - понижающие поверхностное натяжение воды и позволяющие дробить объем воды на более мелкие капли, увеличить смачиваемость водой лесных горючих материалов, обеспечить возможность раствору образовывать сплошной слой на поверх- ности горючего материала с целью изоляции его от кислорода воздуха [4], влияющие на вязкость водного раствора [5] водные растворы термостойких полимеров, образующие стабильные пленки на поверхности горючих материалов [6]. Кроме этого, находят применение неорганические добавки к воде, выступающие в качестве ингибиторов горения: соли аммиака, серной, фосфорной кислот, кремний-, магний-, бор-, железо-, цинк-, медь-, титансодержащие вещества и т. п. [7-20]. Таким образом, появляется возможность реализации комплексного огнетушащего действия при применении комплексных огнетушащих составов.

Все вышеперечисленное обладает собственным набором недостатков, т. к. действие их должно осуществляться в комплексе. Так, низкая температура кипения воды не позволяет ей образовывать стабильные воздухонепроницаемые слои на поверхности разогретых материалов, а введение в объем воды добавок лишь незначительно повышает температуру кипения растворов [21]. Жидкое состояние воды и ее растворов не позволяет ей удерживаться на наклонных и вертикальных поверхностях из-за действия силы тяжести. Термическое разложение лесных горючих материалов с образованием значительного объема горючих и негорючих продуктов распада органического вещества приводит к удалению (сдуванию) ингибирующих веществ (ионов солей) с поверхности горящего материала и прекращению их ингибирующего воздействия.

В работе предлагается несколько иной подход к реализации комплексного огнетушащего действия путем сочетания охлаждающего действия воды с изолирующим действием твердой термостойкой негорючей пленки, получаемой при термическом воздействии на гидрогели - водные растворы неорганических веществ определенного типа. Хорошо известны свойства веществ/материалов формировать стеклообразные кристаллические массы с высокой температурой плавления. К таким веществам относятся соединения на основе кремния, алюминия, магния и т. п. Так, в работе [22] предложено огнетушещее средство на основе кремниевой кислоты, которое обладает способностью под воздействием высокой температуры вспе- 


\section{Природопользование}

ниваться с образованием термостойкой воздухонепроницаемой пленки, что обуславливает огнетушащий эффект. Кремниевая кислота подается в зону горения в виде жидкости - водного раствора, и благодаря достаточной адгезии (липкости) к ЛГМ (химический состав данного огнетушащего вещества соответствует составу широко известного и широко применяемого канцелярского клея), позволяет раствору удерживаться даже на вертикально расположенных поверхностях.

Свойствами образовывать гидрогели обладают многие вещества, оксиды и гидроксиды которых плохо растворимы или нерастворимы в воде, к примеру, оксид и гидроксид алюминия $\left(\mathrm{Al}_{2} \mathrm{O}_{3}\right.$, $\left.\mathrm{Al}(\mathrm{OH})_{3}\right)$. Указанные вещества можно получить взаимодействием соли алюминия - например, сульфата (хлорида, нитрата и т.п.) алюминия - с водой (гидролизом). Сульфат алюминия $\mathrm{Al}_{2}\left(\mathrm{SO}_{4}\right)_{3}$ хорошо растворим в воде $(38,5$ г/100 г воды), что позволяет получить раствор с концентрацией до 38,5 \% (мас.). Но водные растворы солей алюминия не существуют, т.к. мгновенно подвергаются гидролизу с образованием гидроксида алюминия. Тем не менее, прежде чем образовать твердую кристаллическую фазу, гидроксид алюминия образует коллоидный раствор - гидрогель, обладающий стабильностью в течение некоторого времени. Усилить процесс гидролиза способно добавление в раствор бикарбоната натрия (кальцинированной соды) $\mathrm{Na}_{2} \mathrm{CO}_{3}$. Реакция получения гидроксида алюминия соответствует следующему уравнению:

$$
\begin{aligned}
\mathrm{Al}_{2}\left(\mathrm{SO}_{4}\right)_{3}+3 \mathrm{Na}_{2} \mathrm{CO}_{3} & +6 \mathrm{H}_{2} \mathrm{O}=2 \mathrm{Al}(\mathrm{OH})_{3} \downarrow+3 \mathrm{Na}_{2} \mathrm{SO}_{4} \\
& +3 \mathrm{H}_{2} \mathrm{CO}_{3} .
\end{aligned}
$$

Выбор наиболее оптимальных технических параметров способа получения алюмогеля и концентрации алюмогеля в водном растворе был осуществлен на основании проведенных экспериментальных испытаний. В качестве объекта моделирующего ЛГМ был использован искусственный очаг возгорания [23], представляющий собой деревянный штабель в виде куба, состоящий из деревянных брусков сечением $40 \times 40$ мм и длиной 500 мм, сложенный на металлическом коробе размером 500×500 мм и высотой 500 мм, короб устанавливался горизонтально, внизу под штабель помещали металлический поддон соответствующего размера таким образом, чтобы центры штабеля и поддона совпадали. Эксперимент проводился при различных влажностях древесины (от свежесрубленной до суховоздушной), влажностях воздуха (30-50 \%) и температурах воздуха, измеренных в тени $\left(20-35^{\circ} \mathrm{C}\right)$. В поддон заливался слой воды высотой 30 мм. На слой воды наливалась горючая смесь - автомобильный бензин в количестве 1-1,5 литра. Горючая смесь поджигалась факелом и разогревалась в течение 6-7 минут. По истечении этого времени, когда вся поленница охватывалась пламенем, начинался процесс тушения: огнетушащее вещество подавалась в зону горения до полного исчезновения пламени. Далее засекалось время, необходимое для повторного появления открытого пламени в поленнице. Если данное время превысило 10 минут, то пламя считалось погашенным, что свидетельствовало об окончании эксперимента.

Тушение осуществлялось путем подачи огнетушащего раствора в зону горения с помощью лесного ранцевого огнетушителя РП-15 «Ермак» (Россия). Расход огнетушащего средства измерялся по массе ранцевого огнетушителя до и после эксперимента на ручных электронных весах-безмене. Тушение осуществлялось не менее трех раз (для каждого типа огнетушащего состава) для исключения грубых промахов и расчета коридора ошибок.

Концентрацию огнетушащего раствора гидрогеля алюминия в воде подбирали экспериментально, постепенно разбавляя раствор в два раза. Исходный раствор создавался растворением навески сульфата алюминия в 15 литрах воды, что в пересчете на гидроксид с навесками 260, 126, 52 и 26 г. Раствор разбавлялся до тех пор, пока не обнаружилась потеря огнетушащего эффекта. Вода для приготовления раствора использовалась водопроводная (г. Саратов). Навеска сульфата алюминия взвешивалась на электронных технических весах с точностью \pm 1 г. Сульфат алюминия и кальцинированная сода использовались химически чистые. Раствор готовился непосредственно перед проведением эксперимента по огнетушению. В результате проведенного эксперимента были получены следующие экспериментальные результаты: (1) масса огнетушащего вещества, израсходованная на тушение; (2) время, необходимое на огнетушение; 


\section{Природопользование}

(3) количество операций дотушивания после осуществления первичного огнегашения; (4) общее время тушения. Экспериментальные результаты испытания огнетушащих составов представлены в табл. 1.

Анализ представленных результатов показывает выявление огнетушащего эффекта гидрогеля на основе гидроксида алюминия. Так, применяя гидрогель с концентрациями 52-260 г/15 кг воды, удалось снизить расход огнетушащего раствора практически в 3 раза с 13,5 кг для воды до 3,5-4 кг для гидрогеля на основе гидроксида алюминия. Кроме этого, отмечено общее снижение времени тушения пожара (см. табл. 1. кол. 4,6 ) и количества операций дотушивания (см. табл. 1., кол. 5) при применении огнетушащих составов на основе гидроксида алюминия. При использовании водных растворов гидрогеля на основе гидроксида алюминия с концентрацией ниже 52 г /15 кг воды огнетушащий эффект значительно снижался. Получить гидрогель на основе гидроксида алюминия можно двумя способами:

а) гидролизом сульфата алюминия в воде путем растворения его навески;

б) гидролизом сульфата алюминия в растворе бикарбоната натрия (кальцинированной соды).

Благодаря этому в огнетушащем растворе присутствует еще как минимум один компонент это продукт гидролиза сульфата алюминия сульфат натрия. При использовании второго способа получения гидрогеля алюминия к нему добавляется еще и бикарбонат натрия, т. е. огнетушащий раствор становится трехкомпонентным.

Для выявления и подтверждения огнетушащего эффекта именно гидрогеля на основе гидроксида алюминия были проведены аналогичные эксперименты с использованием в качестве огнетушащего состава водных растворов каустической соды $\left(\mathrm{Na}_{2} \mathrm{CO}_{3}\right)$ и сульфата натрия $\left(\mathrm{Na}_{2} \mathrm{SO}_{4}\right)$ - сода входит в состав исходного раствора для создания среды, оптимальной для проведения гидролиза сульфата алюминия, а сульфат натрия является побочным продуктом взаимодействия сульфата алюминия с каустической содой. Концентрации рас- творов были подобраны таким образом, что они соответствуют концентрациям указанных компонентов в огнетушащем гидрогеле. Каустическая сода $\left(\mathrm{Na}_{2} \mathrm{CO}_{3}\right)$ довольно плохо растворима в воде при комнатной температуре и для того чтобы достичь значений растворимости в 9,6 г/100 г воды (насыщенный раствор), указанных в справочниках [24], раствор необходимо нагреть до $80{ }^{\circ} \mathrm{C}$, что довольно трудно реализуемо при приготовлении раствора в полевых условиях, поэтому экспериментальная концентрация раствора соды в воде создавалась близкой к насыщенному - избыточное количество соды помещалось в емкость, и к ней добавлялась вода. Указанную смесь оставляли на 12 чесов, осуществляя ее перемешивание, а затем помещали в ранцевый огнетушитель и использовали в качестве огнетушащего состава. Результаты представлены в табл. 1, они показывают отсутствие сколь-нибудь серьезного огнетушащего эффекта при использовании указанных огнетушащих составов. Таким образом, огнетушащий эффект происходит только за счет присутствия гидроксида алюминия, и в основе процесса тушения древесины и древесных материалов предлагаемым огнетушащим составом лежат следующие физикохимические явления:

1. При попадании водного раствора гидрогеля на основе гидроксида алюминия на поверхность горящей древесины происходит смачивание обугленной поверхности водным раствором;

2. При попадании водного раствора гидрогеля на основе гидроксида алюминия на разогретую поверхность горящей древесины происходит активное испарение воды из водного раствора и образование тугоплавкой твердой пленки стеклообразной массы гидроксида алюминия;

3. Твердая стеклообразная пленка гидроксида алюминия препятствует химическому взаимодействию кислорода воздуха с древесиной, не претерпевает изменений на разогретой поверхности;

В результате взаимодействия предлагаемого огнетушащего состава с огнем и разогретыми поверхностями горючего вещества реализуются следующие огнегасящие факторы: 
Результаты испытаний огнетушащих составов

\begin{tabular}{|c|c|c|c|c|c|}
\hline $\begin{array}{c}\text { № } \\
\text { II/II }\end{array}$ & $\begin{array}{c}\text { Состав огнетушащего } \\
\text { средства }\end{array}$ & $\begin{array}{c}\text { Масса огнету- } \\
\text { шашего вешест- } \\
\text { ва, ушедшая на } \\
\text { тушение мо- } \\
\text { дельного очага } \\
\text { пожара, кг }\end{array}$ & $\begin{array}{c}\text { Время на ту- } \\
\text { шение (пер- } \\
\text { вый подход), с }\end{array}$ & $\begin{array}{c}\text { Количество } \\
\text { подходов }\end{array}$ & $\begin{array}{c}\text { Общее время } \\
\text { тушения мо- } \\
\text { дельного очага } \\
\text { пожара, с }\end{array}$ \\
\hline 1 & Вода & $13,5 \pm 1.0$ & $186 \pm 25$ & $6 \pm 2$ & $248 \pm 25$ \\
\hline 2 & Сода (насыщенный) & $12 \pm 1.0$ & $206 \pm 30$ & $5 \pm 1$ & $276 \pm 25$ \\
\hline 3 & Гидрогель (260 г) & $4 \pm 1.5$ & $63 \pm 15$ & $2 \pm 1$ & $85 \pm 15$ \\
\hline 4 & Гидрогель (130 г) & $4 \pm 1.5$ & $50 \pm 15$ & $2 \pm 1$ & $95 \pm 15$ \\
\hline 5 & Гидрогель (52 г) & $3.5 \pm 1.5$ & $38 \pm 15$ & $3 \pm 1$ & $83 \pm 15$ \\
\hline 6 & Гидрогель (26 г) & $8 \pm 1.5$ & $94 \pm 15$ & $4 \pm 1$ & $122 \pm 20$ \\
\hline 7 & Сульфат натрия (52 г) & $11.5 \pm 1.0$ & $102 \pm 25$ & $6 \pm 2$ & $142 \pm 20$ \\
\hline
\end{tabular}

1. Отъем тепловой энергии из очага пожара на испарение воды из раствора гидрогеля на основе гидроксида алюминия. Тем самым осуществляется передача теплоты, выделяемой при горении, инертному теплоносителю - воде, уменьшая эффективность термического разложения древесины и подавления процесса образования горючих газов и реализации пламенного горения.

2. Устойчивое укрытие твердой поверхности горящей древесины твердой тугоплавкой пленкой оксида алюминия, являющейся диэлектриком и непроницаемой к кислороду воздуха.

Косвенно подтвердить второй огнегасящий фактор можно наблюдением значительного снижения выделения дыма при осуществлении огнетушения с помощью раствора гидроксида алюминия. А после повторного дотушивания дымление практически прекращалось, что свидетельствует о подавлении взаимодействия горючего вещества с кислородом воздуха, осуществляемым в режиме беспламенного горения - являющегося возможным источником повторного воспламенения.

В результате проведенных исследований выявлено:

1. Подобраны оптимальные способы получения гидрогеля и его концентрация в водном растворе, отвечающая минимальному расходу огнетушащего вещества и минимальному количеству реагентов (сульфата алюминия и натриевой соды).
2. Оказалось, что наибольшей огнетушащей способностью и минимальной концентрацией обладает алюмогель, полученный взаимодействием сульфата алюминия с натриевой содой в количествах 52 г сульфата алюминия и 48 г натриевой соды в 15 литрах воды. Использование более высококонцентрированных водных растворов алюмогеля не приводят к существенному уменьшению расхода огнетушащего вещества, а снижение концентрации алюмогеля в водном растворе, наоборот, приводит к перерасходу огнетушащего раствора. Это происходит из-за отсутствия возможности образования сплошной воздухонепроницаемой тугоплавкой пленки при использовании более разбавленного раствора. Компенсировать это можно увеличением расхода раствора.

3. Таким образом, предлагаемое огнегасящее средство является эффективным для тушения лесных и степных пожаров, а также древесины и древесных изделий. Данное огнегасящее средство пригодно как для работ на открытой местности, так и в закрытых помещениях, а также является недорогим и удобным для использования в ранцевых огнетушителях, транспортировки стандартными пожарными средствами пожарными автоцистернами и подачи в зону горения стандартным противопожарным оборудованием: пожарными насосами, рукавами, стволами. 


\section{Природопользование}

\section{Библиографический список}

1. Полевой справочник лесного пожарного [Электронный ресурс]. - Режим доступа: http://www.forestforum.ru/info/fireman.pdf.

2. Справочник добровольного лесного пожарного [Электронный ресурс]. - Режим доступа: https://aviales.ru/files/documents/2013/02/spravochnik.pdf.

3. Бобков, С. А. Физико-химические основы развития и тушения пожаров / С. А. Бобков, А. В. Бабурин, П. В. Комраков. - М. : Академия ГПС МЧС России, 2014. - 210 с.

4. Физико-химические основы развития и тушения пожаров: учеб. пособие / С. С. Тимофеева [и др.]. Иркутск, 2013. - 178 с.

5. Влияние вязкости огнетушащего раствора на эффективность тушения лесных пожаров с помощью авиации / Н. П. Копылов, Е. А. Москвилин, Д. В. Федоткин, П. А. Стрижак // Лесотехнический журнал. 2016. - № 4. - С. 62-67.

6. Лобанов, Ф. И. Применение полимерных материалов для повышения эффективности пожаротушения / Ф. И. Лобанов // Пожаровзрывобезопасность. - 2004. - № 1. - С. 64-69.

7. Jimenez, M. Intumescent fire protective coating: Toward a better understanding of their mechanism of action / M. Jimenez, S. Duquesne, S. Bourbigot // Thermochimica Acta. - 2006. - Vol. 449. - P. 16-26.

8. Testing the retardancy effect of various inorganic chemicals on smoldering combustion of Pinus halepensis needles / S. Liodakis, D. Vorisis, I. P. Agiovlasitis // Thermochimica Acta. - 2006. - Vol. 444. - P. 157-165.

9. Ash properties of Pinus halepensis needles treated with diammonium phosphate / S. Liodakis, G. Katsigiannis, T. Lymperopoulou // Thermochimica Acta. - 2007. - Vol. 453. - P. 136-146.

10. Testing the fire retardancy of Greek minerals hydromagnesite and huntite on WUI forest species Phillyrea latifolia L. / S. Liodakis, I. Antonopoulos, I. P. Agiovlasitis, T. Kakardakis // Thermochimica Acta. - 2008. Vol. 469. - P. 43-51.

11. Fire retardancy impact of sodium bicarbonate on ligno-cellulosic materials / D. Bakirtzis, M. A. Delichatsios, S. Liodakis, W. Ahmed // Thermochimica Acta. - 2009. - Vol. 486. - P. 11-19.

12. Synergistic effect of iron and intumescent flame retardant on shape-stabilized phase change material / P. Zhang, Y. Hu, L. Song, H. Lu, J. Wang, Q. Liu // Thermochimica Acta. - 2009. - Vol. 487. - P. 74-79.

13. Flame retardancy mechanisms of bisphenol A bis(diphenyl phosphate) in combination with zinc borate in bisphenol A polycarbonate/acrylonitrile-butadiene-styrene blends / K. H. Pawlowski, B. Schartel, M. A. Fichera, C. Joger // Thermochimica Acta. - 2010. - Vol. 498. - P. 92-99.

14. A novel durable flame-retardant cotton fabric using sodium hypophosphite, nano $\mathrm{TiO}_{2}$ and maleic acid [Text] / F. Lessan, M. Montazer, M.B. Moghadam // Thermochimica Acta.- 2011.- Vol. 520.- pp. $48-54$.

15. Synthesis and carbonization chemistry of a phosphorous-nitrogen based intumescent flame retardant / H. Ma, Z. Fang // Thermochimica Acta. - 2012. - Vol. 543. - P. 130-136.

16. The effect of some wood preservatives on the thermal degradation of Scots pine / E. D. Tomaka, E. Baysal, H. Peker // Thermochimica Acta. - 2012. - Vol. 547. - P. 76-82.

17. ATR investigation of the mass residue from the pyrolysis of fire retarded lignocellulosic materials / D. Bakirtzis, V. Tsapara, S. Liodakis, M.A. Delichatsios // Thermochimica Acta. - 2012. - Vol. 550. - P. 48-52.

18. Thermal characterization of new fire-insulating materials from industrial inorganic $\mathrm{TiO}_{2}$ wastes / S.M. PerezMoreno, M. J. Gazquez, A. G. Barneto, J. P. Bolivar // Thermochimica Acta. - 2013. - Vol. 552. - P. 114-122.

19. Thermal analysis of Pinus sylvestris L. wood samples treated with anew gel-mineral mixture of short- and long-term fire retardants [Text] / S. Liodakis, V. Tsapara, I. P. Agiovlasitis, D. Vorisis // Thermochimica Acta. 2013. - Vol. 568. - P. 156-160.

20. Aluminium diethylphosphinate versus ammonium polyphosphate: Acomprehensive comparison of the chemical interactions duringpyrolysis in flame-retarded polyolefine/poly(phenylene oxide) / A. Sut, S. Greiser, C. Jager, B. Schartel // Thermochimica Acta. - 2016. - Vol. 640. - P. 74-84. 


\section{Природопользование}

21. Стромберг, А. Г. Физическая химия: учеб. для хим. спец. Вузов / А. Г. Стромберг, Д. Л. Семченко ; под ред. А. Г. Стромберга. - 3-е изд., испр. и доп. - М. : Высш. шк., 1999. - 527 с.

22. Водный раствор для тушения пожаров: пат. 2275951 Рос. Федерация: A62D1/00/ Лотов В. А., Смирнов А. П., Лотова Л. Г.; заявитель Государственное образовательное учреждение высшего профессионального образования Томский политехнический ун-т. - № 2004132686/15; заявл. 09.11.04 ; опубл. 10.05.06, Бюл. № 13.

23. ГОСТ Р 53280.4-2009. Установки пожаротушения автоматические. Огнетушащие вещества. Часть 4. Порошки огнетушащие общего назначения. Общие технические требования и методы испытаний - Введ. 200901-01. - М.: Изд-во стандартов, 2008. - 27 с.

24. Справочник химика: в 7 т. Т. 3 /под ред. Б. П. Никольского. - Л. : Химия, 1966. -1143 с.

\section{References}

1. Polevoj spravochnik lesnogo pozharnogo [Wild fireman handbook]. Available at: http://www.forestforum.ru/info/fireman.pdf (In Russian) (accessed 01 November 2018).

2. Spravochnik dobrovol'nogo lesnogo pozharnogo [Wild fireman volonteer handbook] Available at: https://aviales.ru/files/documents/2013/02/spravochnik.pdf (In Russian) (accessed 01 November 2018).

3. Bobkov S. A. Fiziko-himicheskie osnovy razvitiya i tusheniya pozharov [Physical and chemical basis of fires and fire extinguishing]. Moscow, 2014, 210 p. (In Russian).

4. Fiziko-himicheskie osnovy razvitiya i tusheniya pozharov: A Tutorial [Physical and chemical basis of fires and fire extinguishing]. Irkutsk, 2013, 178 p. (In Russian).

5. Kopylov N. P., Moskvilin E. A., Fedotkin D. V. et al. Vliyanie vyazkosti ognetushashchego rastvora na ehffektivnost' tusheniya lesnyh pozharov s pomoshch'yu aviacii [The effect of the viscosity of the fire extinguishing solution on the effectiveness of extinguishing forest fires with the help of aviation]. // Lesotekhnicheskij zhurnal [Forest engineering journal]. 2016, no. 4, pp. 62-67.

6. Lobanov F. I. Primenenie polimernyh materialov dlya povysheniya ehffektivnosti pozharotusheniya [Polymeric materials to improve the efficiency of fire extinguishing usage]. Pozharovzryvobezopasnost' [Fire and explosion safety], 2004, no. 1, pp. 64-69.

7. Jimenez M., Duquesne S., Bourbigot S. Intumescent fire protective coating: Toward a better understanding of their mechanism of action. Thermochimica Acta, 2006, Vol. 449, pp. 16-26.

8. Liodakis S., Vorisis D., Agiovlasitis I. P. Testing the retardancy effect of various inorganic chemicals on smoldering combustion of Pinus halepensis needles. Thermochimica Acta, 2006, Vol. 444, pp. 157-165.

9. Liodakis S., Katsigiannis G., Lymperopoulou T. Ash properties of Pinus halepensis needles treated with diammonium phosphate. Thermochimica Acta, 2007, Vol. 453, pp. 136-146.

10. Liodakis S., Antonopoulos I., Agiovlasitis I. P., Kakardakis T. Testing the fire retardancy of Greek minerals hydromagnesite and huntite on WUI forest species Phillyrea latifolia L. Thermochimica Acta, 2008, Vol. 469, pp. 43-51.

11. Bakirtzis D., Delichatsios M. A., Liodakis S., Ahmed W. Fire retardancy impact of sodium bicarbonate on ligno-cellulosic materials. Thermochimica Acta, 2009, Vol. 486, pp. 11-19.

12. Zhang P., Hu Y., Song L., Lu H., Wang J., Liu Q. Synergistic effect of iron and intumescent flame retardant on shape-stabilized phase change material. Thermochimica Acta, 2009, Vol. 487, pp. 74-79.

13. Pawlowski K. H., Schartel B., Fichera M. A., Joger C. Flame retardancy mechanisms of bisphenol A bis(diphenyl phosphate) in combination with zinc borate in bisphenol A polycarbonate/acrylonitrile-butadienestyrene blends. Thermochimica Acta, 2010, Vol. 498, pp. 92-99.

14. Lessan F., Montazer M., Moghadam M. B. A novel durable flame-retardant cotton fabric using sodium hypophosphite, nano $\mathrm{TiO}_{2}$ and maleic acid. Thermochimica Acta, 2011, Vol. 520, pp. 48-54. 
15. Ma H., Fang Z. Synthesis and carbonization chemistry of a phosphorous-nitrogen based intumescent flame retardant. Thermochimica Acta, 2012, Vol. 543, pp. 130-136.

16. Tomaka E. D., Baysal E., Peker H. The effect of some wood preservatives on the thermal degradation of Scots pine. Thermochimica Acta, 2012, Vol. 547, pp. 76-82.

17. Bakirtzis D., Tsapara V., Liodakis S., Delichatsios M. A. ATR investigation of the mass residue from the pyrolysis of fire retarded lignocellulosic materials. Thermochimica Acta, 2012, Vol. 550, pp. 48-52.

18. Perez-Moreno S. M., Gazquez M. J., Barneto A. G., Bolivar J. P. Thermal characterization of new fire-insulating materials from industrial inorganic $\mathrm{TiO}_{2}$ wastes. Thermochimica Acta, 2013, Vol. 552, pp. 114-122.

19. Liodakis S., Tsapara V., Agiovlasitis I. P., Vorisis D. Thermal analysis of Pinus sylvestris L. wood samples treated with anew gel-mineral mixture of short- and long-term fire retardants. Thermochimica Acta, 2013, Vol. 568, pp. 156-160.

20. Sut A., Greiser S., Jager C., Schartel B. Aluminium diethylphosphinate versus ammonium polyphosphate: Acomprehensive comparison of the chemical interactions duringpyrolysis in flame-retarded polyolefine/poly(phenylene oxide). Thermochimica Acta, 2016, Vol. 640, pp. 74-84.

21. Stromberg A. G., Semchenko D. L. Fizicheskaya himiya [Physical chemistry]. A tutorial. Third edition. Moscow, 1999, 527 p. (In Russian).

22. Lotov V. A. et al. Vodnyj rastvor dlya tusheniya pozharov [Water solution for extinguishing fires]. Patent RF, no. $2275951,2006$.

23. State Standard 53280.4-2009. Installation of fire extinguishing automatic. Extinguishing agents. Part 4. General purpose fire extinguishing powders. General technical requirements and test methods Moscow, Standartinform Publ., 2008. 27 p. (In Russian)

24. Spravochnik himika [Chemical directory]: in 7 vol. Vol. 3. Leningrad, 1966, 1143 p.

\section{Сведения об авторах}

Ивченко Ольга Александровна - аспирант факультета инженерии и природообустройства ФГБОУ ВО «Саратовский государственный аграрный университет имени Н.И. Вавилова», г. Саратов, Российская Федерация; e-mail: olgalexan@yandex.ru.

Панкин Кирилл Евгеньевич - доцент ФГБОУ ВО «Саратовский государственный аграрный университет имени Н.И. Вавилова», кандидат химических наук, г. Саратов, Российская Федерация; е-таil: texmexium@mail.ru.

\section{Information about authors}

Ivchenko Olga Aleksndrovna - PhD student, Department of technosphere safety and transport-technology machines, FSBEI HE “Saratov State Agrarian University named after N.I. Vavilov”, Saratov, Russian Federation, e-mail: olgalexan@yandex.ru.

Pankin Kirill Evgen'evich - Associated Professor of Safety, Department of technosphere safety and transporttechnology machines, FSBEI HE "Saratov State Agrarian University named after N.I. Vavilov" PhD (Chemistry), Associated Professor, Saratov, Russian Federation, e-mail: texmexium@mail.ru. 